\title{
Caracterización bromatológica y evaluación de la actividad antimi- crobiana en cáscara de banano Ecuatoriano (Musa paradisiaca)
}

\section{(Bromatological characterization and evaluation of the antimi- crobial activity of Ecuadorian banana peel (Musa paradisiaca))}

Gabriela Pilco ${ }^{1}$, Dayana Borja ${ }^{1}$, Lorena Goetschel ${ }^{1}$, Paulette Andrade ${ }^{2}$, Jorge Irazabal ${ }^{2}$, Paúl Vargas-Jentzsch ${ }^{3}$, José Luis Guil-Guerrero ${ }^{4}$, Víctor Rueda-Ayala ${ }^{5}$, Luis Ramos ${ }^{6}$

\begin{abstract}
Resumen:
Se determinó la composición bromatológica de cáscara de banano (Musa paradisiaca) producida en Ecuador y se identificaron las fracciones y grupos fitoquímicos responsables de su actividad antimicrobiana. El análisis bromatológico determinó un porcentaje de humedad del $88,94 \%$ y $11,06 \%$ de sólidos totales $(1,55 \%$ ceniza, $0,47 \%$ grasa, $0,74 \%$ proteína, $0,87 \%$ fibra y $8,3 \%$ carbohidratos totales). Para la obtención de las fracciones se aplicaron dos métodos de extracción por maceración. El primero usó cuatro solventes de diferente polaridad como éter de petróleo, cloroformo, acetato de etilo y agua. Los extractos obtenidos fueron sometidos a pruebas de tamizaje fitoquímico identificándose la presencia de compuestos grasos, esteroles, triterpenos, saponinas y taninos. El segundo método usó como solvente etanol al $70 \%$ y se generaron cinco fracciones. Ensayos de actividad antimicrobiana por el método de difusión en agar se realizaron en Staphylococcus aureus y Escherichia coli mediante el extracto crudo etanólico y sus fracciones, se evidenció actividad microbiológica. Ensayos de tamizaje fitoquímico y cromatografía en capa fina se realizaron sobre cada fracción y extracto identificándose los principales grupos de compuestos responsables de la actividad antimicrobiana.
\end{abstract}

Palabras clave: banano; musa paradisiaca; tamizaje fitoquímico; actividad microbiológica.

\begin{abstract}
:
The bromatological composition of banana peel (Musa paradisiaca) produced in Ecuador was determined and the fractions and phytochemical groups responsible for its antimicrobial activity were identified. The bromatological analysis determined a humidity of $88.94 \%$ and $11.06 \%$ of total solids $(1.55 \%$ of ash, $0.47 \%$ of fat, $0.74 \%$ of protein, $0.87 \%$ of fiber and $8.3 \%$ total carbohydrates). To obtain the fractions, two methods of maceration were applied. The first used four solvents of different polarities, such as petroleum ether, chloroform, ethyl acetate and water. The extracts were subjected to phytochemical screening tests that identify the presence of fatty compounds, sterols, triterpenes, saponins and tannins. The second method used $70 \%$ ethanol as solvent and five fractions were generated. Tests of antimicrobial activity by the agar diffusion method were performed in Staphylococcus aureus and Escherichia coli using the crude ethanolic extract and its fractions, microbiological activity was evidenced. Phytochemical screening assays and chromatography were performed on each fraction and extract identifying the main groups of compounds responsible for the antimicrobial activity.
\end{abstract}

Keywords: banana; musa paradisiaca; phytochemical screening; antimicrobial activity.

\footnotetext{
1 Universidad Central del Ecuador, Quito, Ecuador (\{gtpilco, dpborja, mlgoetschel\} @uce.edu.ec)

2 Agencia Ecuatoriana de Aseguramiento de la Calidad del Agro, Quito, Ecuador (\{paulette.andrade, jorge.irazabal\}@agrocalidad.gob.ec)

${ }^{3}$ Escuela Politécnica Nacional, Quito, Ecuador (paul.vargas@epn.edu.ec)

4 Universidad de Almería, Almería, España (jlguil@ual.es)

${ }^{5}$ Norwegian Institute of Bioeconomy Research, NIBIO Særheim, Norway (patovicnsf@gmail.com)

6 Universidad Tecnológica Equinoccial, CIAL, Quito, Ecuador (luis.ramos@ute.edu.ec)
} 


\section{Introducción}

En la actualidad, millones de toneladas de subproductos agrícolas son generados a diario. Su manejo inadecuado presenta consecuencias negativas para el medio ambiente, así como también importantes implicaciones sociales y económicas. Sin embargo, si se aprovechan los beneficios potenciales de estos subproductos, se aportaría enormemente a la agenda de desarrollo sostenible establecida como una medida del uso responsable de los recursos del planeta. Un importante grupo de subproductos que contienen compuestos con propiedades nutritivas y actividad biológica es el derivado de productos tropicales (GuilGuerrero et al, 2016a; Guil-Guerrero et al., 2016b; Guil-Guerrero et al., 2016c). Ecuador es el primer país exportador de banano de calidad a nivel mundial con cerca del $30 \%$ de la oferta mundial, lo cual representa el $15 \%$ de las exportaciones totales (PROECUADOR, 2016). Factores climáticos y geográficos propician la producción de esta fruta en el país durante todo el año. Durante 2013 se produjeron aproximadamente 5995527 toneladas métricas, mientras que en el 2014 la cifra ascendió a 6.907.376 toneladas, lo que revela la tendencia de crecimiento de producción de esta fruta para los próximos años (MAGAP 2014).

Los subproductos obtenidos de la producción de banano constituyen una fuente de biomasa fácilmente utilizable como materia prima en el desarrollo de nuevos productos. Estos productos proveen un valor añadido a materiales tradicionalmente considerados como "desechos". Pectinas, celulosa, minerales, carbohidratos, colorantes naturales, compuestos antioxidantes, aromas, entre otros, son varios de los muchos compuestos que han sido identificados en las cáscaras del banano y han sido además utilizados en la industria. En los últimos años, el interés en este subproducto ha crecido, debido a que varios estudios han reportado la presencia de compuestos bioactivos con actividad antimicrobiana y antifúngica (Mordi et al., 2016; Niamah, 2014; Chinnappan et al., 2013). En consecuencia, la comercialización de banano podría ser doblemente aprovechada: económicamente para el consumo con fines nutricionales e industriales, aprovechando la disponibilidad potencial de varios compuestos naturales incorporados en los subproductos de la fruta (por ejemplo de la cáscara) y a los cuales se generan en la etapa del cultivo (hojas, tronco, brácteas, raíces).

Este estudio tiene como objetivo determinar la composición bromatológica y la identificación de los principales grupos fitoquímicos presentes en la cáscara de banano ecuatoriano, con la finalidad de reconocer sus aplicaciones potenciales, contribuyendo a la disminución de residuos agrícolas. Como hipótesis (H1, alternativa) se propone que los extractos de la cáscara de banano reducen la actividad antimicrobiana en las bacterias Staphylococcus aureus y Escherichia coli, lo que podría ofertar una alternativa a la problemática de resistencia a los antibióticos sintéticos.

\section{Metodología}

El estudio se realizó en una muestra de banano (Musa paradisiaca) de origen ecuatoriano en estado de completa maduración y disponible en un mercado de la ciudad de Quito. Aleatoriamente se tomaron cuatro muestras de $2 \mathrm{~kg}$ cada una para el análisis bromatológico y una muestra de $20 \mathrm{~kg}$ para el fraccionamiento e identificación de los grupos de compuestos bioactivos.

\subsection{Análisis bromatológico}

Los procedimientos usados para la determinación de la composición de la cáscara de banano fueron los establecidos en los métodos oficiales normalizados de la AOAC (AOAC, 2000). Así, se aplicaron métodos gravimétricos para determinar humedad y sólidos totales (925.10), determinación por vía seca de ceniza (923.03), extracción por solvente 
para grasa (991.36), método Kjeldahl para proteína (981.10) y NTE INEN 542:1980 para Fibra. Los carbohidratos se determinaron por cálculo.

\subsection{Extracción}

Se realizaron dos tipos de extracción. El primer método consistió en una 'maceración sucesiva' con cuatro solventes de polaridad creciente: éter de petróleo, cloroformo, acetato de etilo y agua. El segundo método consistió en la obtención de un extracto etanólico crudo por maceración ('maceración etanólica') que posteriormente fue sometido a un proceso de fraccionamiento. Previo al proceso de extracción, las cáscaras fueron limpiadas y secadas a $35^{\circ} \mathrm{C}$ por 24 horas.

Para la maceración sucesiva, se pesaron $200 \mathrm{~g}$ de cáscara seca y se adicionaron $400 \mathrm{ml}$ de éter de petróleo. Se maceró durante 48 horas a temperatura ambiente y y se protegió de la luz. Posteriormente se filtró el extracto obtenido, se concentró en vacío hasta alcanzar un volumen de $200 \mathrm{ml}$ y luego el residuo sólido se evaporo al ambiente bajo cabina de extracción. La maceración se repitió utilizando un solvente de extracción diferente en cada oportunidad (cloroformo, acetato de etilo y agua). Para la maceración etanólica se pesaron $200 \mathrm{~g}$ de muestra seca y se adicionaron $400 \mathrm{ml}$ de etanol al $70 \%$, se maceró durante 48 horas a temperatura ambiente y en sombra. A continuación, se filtró y el extracto etanólico se concentró hasta un volumen final de $200 \mathrm{ml}$ (extracto crudo). Se tomaron alícuotas del extracto crudo y se concentraron nuevamente hasta obtener 4 diferentes factores de concentración: 1, 2, 5, 10 (Tabla 1). Se repitió el procedimiento de extracción hasta obtener un nuevo extracto crudo que se usó en el proceso de fraccionamiento. Todos los extractos obtenidos fueron almacenados en refrigeración $\left(0^{\circ} \mathrm{C}\right)$ hasta su uso.

Tabla 1. Diluciones del extracto etanólico de banano

\begin{tabular}{|l|r|r|r|}
\hline & $\begin{array}{c}\text { Volumen del } \\
\text { extracto crudo }(\mathbf{m L})\end{array}$ & $\begin{array}{c}\text { Volumen final después } \\
\text { de concentración }(\mathbf{m L})\end{array}$ & $\begin{array}{c}\text { Factor de } \\
\text { concentración }\end{array}$ \\
\hline Blanco (etanol al 70\%) & - & - & - \\
\hline Concentración 1 (C1) & 5 & 5 & 1 \\
\hline Concentración 2 (C2) & 20 & 10 & 5 \\
\hline Concentración 3 (C3) & 50 & 10 & 10 \\
\hline Concentración 4 (C4) & 100 & 10 & 5 \\
\hline
\end{tabular}

\subsection{Ensayos de actividad antimicrobiana}

El ensayo de actividad antimicrobiana usado fue una adaptación del método de difusión en discos o antibiograma propuesto por Clinical and Laboratory Standars Institute (2012) que consistió en las siguientes etapas.

Preparación del inóculo por método directo de inoculación a partir de colonia aislada: se suspendieron colonias de una placa de cultivo no selectivo de 18 horas de incubación en caldo nutritivo. La densidad de la suspensión se ajustó a 0,5 de la escala McFarland.

Inoculación en placas: se sembró por hisopado en las placas de agar Muller-Hilton el inóculo previamente preparado. La siembra se realizó dentro de los 15 minutos siguientes al ajuste de densidad del inóculo.

Aplicación de los discos con antimicrobianos en las placas inoculadas: se realizaron discos de papel filtro de $6 \mathrm{~mm}$ de diámetro, se esterilizaron y posteriormente fueron impregnados con las diferentes concentraciones de los extractos y las fracciones. Se colocaron los discos con antimicrobiano sobre la superficie inoculada de la placa con la ayuda de una pinza estéril aplicando ligera presión y a una distancia adecuada.

Incubación de las placas y lectura de resultados: las placas invertidas fueron incubadas por 18 horas a $35^{\circ} \mathrm{C}$. Cumplido este tiempo, se midieron los halos de inhibición generados. Las lecturas se aproximaron al valor entero en milímetros más cercano. 


\subsection{Fraccionamiento}

En el método de maceración sucesiva, los compuestos presentes en la cáscara de banano fueron extraídos en función de la polaridad del solvente. A cada uno de los extractos obtenidos se le considera también como fracción: el extracto o fracción etérea, extracto o fracción clorofórmica, extracto o fracción de acetato de etilo y el extracto o fracción acuosa. El extracto etanólico logrado por el método de maceración etanólica se dividió en cuatro partes iguales, cada una de las cuales fue fraccionada mediante solventes de diferente polaridad.

a) Fraccionamiento con cloroformo: se llevó una porción del extracto a un $\mathrm{pH}$ de 2-3 usando una solución de $\mathrm{HCl}$ al $5 \%$. Se adicionó $\mathrm{NaOH}$ al $20 \%$ gota a gota hasta alcanzar un pH entre 10 a 12. Se transfirió el extracto alcalinizado a un embudo de separación. Se extrajo con cloroformo mediante 3 lavados, separando la fase orgánica cada vez. Con un evaporador rotatorio, se concentró la fase orgánica hasta sequedad y se reconstituyó con agua estéril para obtener la fracción A. A partir de la fracción $A$ se realizaron las pruebas de identificación de grupos fitoquímicos y el ensayo de actividad antimicrobiana.

b) Fraccionamiento con éter de petróleo: se transfirió una porción del extracto a un embudo de separación y se extrajo con éter de petróleo, realizando 3 lavados con el solvente y separando la fase orgánica cada vez. Se guardó la fase acuosa para su posterior extracción. Mediante un evaporador rotatorio, se concentró la fase orgánica hasta sequedad y se la reconstituyó con agua estéril. Así se obtuvo la fracción $B$, a partir de la cual se realizaron las pruebas de identificación de grupos fitoquímicos y el ensayo de actividad antimicrobiana.

c) Fraccionamiento con metanol/agua (50/50): se maceró la fase acuosa previamente obtenida durante 24 horas con una mezcla de metanol/agua (50/50). Se filtró al vacío, el líquido filtrado obtenido se concentró a sequedad y se reconstituyó con agua estéril, obteniendo de esta forma la fracción $C$. Al residuo sólido logrado de la filtración al vacío se redisolvío en cloroformo, se concentró a sequedad y reconstituyó con agua estéril, de esta forma se obtuvo la fracción $D$. A partir de estas dos fracciones se realizaron las pruebas de identificación de grupos fitoquímicos y el ensayo de actividad antimicrobiana.

d) Fraccionamiento con acetato de plomo y cloroformo: se añadió gota a gota una solución de acetato de plomo al $20 \%$ sobre una porción del extracto hasta que no se apreció la formación de precipitado. Se filtró por gravedad, desechó el precipitado y al filtrado se extrajo con cloroformo, realizando 3 lavados con el solvente y separando la fase orgánica cada vez. Se filtró el extracto clorofórmico mediante sulfato de sodio anhidro, se concentró el filtrado obtenido a sequedad y se reconstituyó con agua estéril. Se obtuvo entonces la fracción $E$, a partir de la cual se realizaron las pruebas de identificación de grupos fitoquímicos y el ensayo de actividad antimicrobiana.

\subsection{Tamizaje fitoquímico}

Las fracciones obtenidas por el método de maceración sucesiva fueron analizadas para la identificación de los grupos fitoquímicos presentes (alcaloides, terpenos, esteroides, antocianos, flavonoides, taninos, saponinas, etc.) mediante ensayos cualitativos específicos, como se detalla en la Tabla 2. Las fracciones obtenidas a partir del extracto crudo (maceración etanólica) fueron analizada según los ensayos propuestos en la Tabla 3. 
Tabla 2. Ensayos específicos para la detección de grupos fitoquímicos en las fracciones generadas a través del primer método de extracción

\begin{tabular}{|c|c|c|c|c|}
\hline $\begin{array}{l}\text { Solvente } \\
\text { Extractante }\end{array}$ & Fracción & Ensayo de & $\begin{array}{l}\text { Grupo Fitoquímico } \\
\text { a detectar }\end{array}$ & Detección \\
\hline \multirow[t]{4}{*}{ Éter de petróleo } & \multirow[t]{4}{*}{ FEP } & $\begin{array}{l}\text { Libermand- } \\
\text { Burchard }\end{array}$ & $\begin{array}{ll}\text { Triterpenos } & y / 0 \\
\text { esteroides } & \end{array}$ & $\begin{array}{l}\text { Formación de anillo azul } \\
\text { intenso (punto de } \\
\text { contacto). }\end{array}$ \\
\hline & & Sudan & Aceites y grasas & $\begin{array}{l}\text { Gotas o película } \\
\text { coloreada de rojo. }\end{array}$ \\
\hline & & Baljet & $\begin{array}{ll}\text { Lactonas } & y \\
\text { cumarinas } & \end{array}$ & $\begin{array}{l}\text { Precipitado o coloración } \\
\text { roja. }\end{array}$ \\
\hline & & Dragendorff & Alcaloides & $\begin{array}{l}\text { Precipitado color rojo } \\
\text { ladrillo. }\end{array}$ \\
\hline \multirow[t]{3}{*}{ Cloroformo } & \multirow[t]{3}{*}{ FCF } & $\begin{array}{l}\text { Libermand- } \\
\text { Burchard }\end{array}$ & $\begin{array}{ll}\text { Triterpenos } & y / 0 \\
\text { esteroides } & \end{array}$ & $\begin{array}{l}\text { Formación de anillo azul } \\
\text { intenso (punto de } \\
\text { contacto). }\end{array}$ \\
\hline & & cloruro férrico & Taninos & $\begin{array}{ll}\text { Azul: } & \text { taninos } \\
\text { pirocatecólicos } & \\
\text { Verde: } & \text { taninos } \\
\text { pirogalotánicos } & \\
\end{array}$ \\
\hline & & Sudan & Aceites y grasas & $\begin{array}{l}\text { Gotas o película } \\
\text { coloreada de rojo. }\end{array}$ \\
\hline \multirow[t]{3}{*}{ Acetato de etilo } & \multirow[t]{3}{*}{ FAE } & Shhinoda & Flavonoides & $\begin{array}{l}\text { Colores intensos: } \\
\text { amarillo, naranja, o rojo }\end{array}$ \\
\hline & & cloruro férrico & Taninos & $\begin{array}{ll}\text { Azul: } & \text { taninos } \\
\text { pirocatecólicos } & \\
\text { Verde: } & \text { taninos } \\
\text { pirogalotánicos } & \\
\end{array}$ \\
\hline & & $\begin{array}{l}\text { Libermand- } \\
\text { Burchard }\end{array}$ & $\begin{array}{l}\text { Triterpenos } \\
\text { esteroides }\end{array}$ & $\begin{array}{l}\text { Formación de anillo azul } \\
\text { intenso (punto de } \\
\text { contacto). }\end{array}$ \\
\hline \multirow[t]{4}{*}{ Agua } & \multirow[t]{4}{*}{ FAC } & Shinoda & Flavonoides & $\begin{array}{l}\text { Colores intensos: } \\
\text { amarillo, naranja, o rojo }\end{array}$ \\
\hline & & cloruro férrico & Taninos & $\begin{array}{ll}\text { Azul: } & \text { taninos } \\
\text { pirocatecólicos } & \\
\text { Verde: } & \text { taninos } \\
\text { pirogalotánicos } & \\
\end{array}$ \\
\hline & & espuma & Saponinas & $\begin{array}{l}\text { Espuma superficial de } \\
\text { más de } 2 \mathrm{~mm} \text { de altura } \\
\text { que persiste por más de } \\
2 \text { minutos }\end{array}$ \\
\hline & & Dragendorff & Alcaloides & $\begin{array}{l}\text { Precipitado color rojo } \\
\text { ladrillo. }\end{array}$ \\
\hline
\end{tabular}

Fuente: Adaptado de Matos (2009)

\subsection{Análisis estadístico}

Las diferentes concentraciones obtenidas a partir del extracto crudo de maceración etanólica fueron usadas en el ensayo de actividad antimicrobiana. Las determinaciones se realizaron por triplicado y con los halos de inhibición obtenidos se realizó un análisis de varianza (ADV) utilizando una significación estadística del 95\%. Los factores en estudio para los ensayos de actividad microbiana en las diferentes concentraciones del extracto crudo (Tabla 1) fueron: tipo de bacterias, concentraciones del extracto crudo y la interacción entre ellos. Al considerar que la concentración 4 del extracto etanólico crudo (C4) generó una mayor inhibición en el crecimiento de las bacterias, el extracto etanólico crudo se 
fraccionó nuevamente, concentró y reconstituyó mediante el mismo procedimiento descrito anteriormente (sección 2.4), obteniéndose el factor de concentración de 10. A partir de estas fracciones se repitieron el ensayo de actividad antimicrobiana y el ADV, este último para los factores tipo de bacterias, tipo de fracción e interacción entre ambos. En caso de significación estadística de los factores, se realizó la prueba de Tukey para los promedios de los efectos obtenidos con las distintas concentraciones y fracciones.

Tabla 3. Ensayos específicos para la detección de grupos fitoquímicos en las fracciones generadas a partir del extracto crudo

\begin{tabular}{|c|c|c|c|}
\hline & & & \\
\hline Fracción & Ensayo de & Grupo Fitoquímico a Detectar & Detección \\
\hline Fracción A & Mayer & Alcaloides & Precipitado blanco coposo \\
\hline & Wagner & & Precipitado color café \\
\hline & Dragendorff & & Precipitado color rojo ladrillo \\
\hline Fracción B & $\begin{array}{l}\text { Libermand- } \\
\text { Burchard }\end{array}$ & Triterpenos y esteroides & $\begin{array}{l}\text { Formación de anillo azul } \\
\text { intenso (punto de contacto) }\end{array}$ \\
\hline $\begin{array}{l}\text { Fracción C } \\
\text { y D }\end{array}$ & Shinoda & Flavonoides & $\begin{array}{l}\text { Colores intensos: amarillo, } \\
\text { naranja, o rojo }\end{array}$ \\
\hline & $\begin{array}{l}\text { Reacción en } \\
\text { medio alcalino }\end{array}$ & & $\begin{array}{l}\text { KOH: amarillo - naranja } \\
\text { FeCl3: Coloración Azul } \\
\text { verdosa }\end{array}$ \\
\hline & Antocianos & Antocianos & $\begin{array}{l}\text { HCl: rojo } \\
\text { NH3: cambia a azul }\end{array}$ \\
\hline & Bontrager & Antraquinonas & Coloración rosa capa acuosa \\
\hline & Cloruro férrico & Taninos (hidrolizables y no & Precipitado blanco floculento \\
\hline & $\begin{array}{l}\text { Gelatina } \\
\text { salada }\end{array}$ & lizables) & Precipitado blanco floculento \\
\hline & $\begin{array}{l}\text { Reacción de } \\
\text { Stiasny }\end{array}$ & & \\
\hline & Espuma & Saponinas & $\begin{array}{l}\text { Espuma superficial de más de } \\
2 \text { mm de altura que persiste } \\
\text { por más de } 2 \text { minutos }\end{array}$ \\
\hline Fracción E & Baljet & Lactonas y cumarinas & Precipitado o coloración roja \\
\hline & $\begin{array}{l}\text { Reacción de } \\
\text { Kedde }\end{array}$ & Glucósidos cardiotónicos & $\begin{array}{lll}\begin{array}{l}\text { Desarrollo de coloración } \\
\text { violeta }\end{array} & \\
\end{array}$ \\
\hline
\end{tabular}

Fuente: Adaptado de Matos (2009)

\section{Resultados y discusión}

\subsection{Análisis bromatológico}

Los resultados generales del análisis bromatológico de las muestras evaluadas se muestran en la Tabla 4. El agua constituyó el principal componente de la cáscara de banano en aproximadamente un $89 \%$. Los sólidos totales, que incluyen grasa, proteína, ceniza y carbohidratos, conformaron aproximadamente una décima parte del peso total de las cáscaras de banano analizadas. La fracción sólida aprovechable contiene en promedio baja cantidad de grasa $0.47 \%$, mientras que el $0.74 \%$ correspondió a proteína y el 1.55 $\%$ de cenizas, donde se encuentran los macro y micronutrientes., lo cual indica un considerable potencial con fines nutricionales. El porcentaje de carbohidratos fue en promedio el $8.3 \%$, donde se encuentra una gran cantidad de compuestos orgánicos también aprovechables. 
Tabla 4. Resultados generales del análisis bromatológico de la cáscara de banano

\begin{tabular}{|l|l|l|l|l|l|l|l|}
\hline Muestra & $\begin{array}{l}\text { Humedad } \\
(\%)\end{array}$ & $\begin{array}{l}\text { Sólidos } \\
\text { Totales } \\
(\%)\end{array}$ & $\begin{array}{l}\text { Grasa } \\
(\%)\end{array}$ & $\begin{array}{l}\text { Proteína } \\
(\%)\end{array}$ & $\begin{array}{l}\text { Ceniza } \\
(\%)\end{array}$ & $\begin{array}{l}\text { Fibra } \\
(\%)\end{array}$ & $\begin{array}{l}\text { Carbohidratos } \\
(\%)\end{array}$ \\
\hline M1 & 89,21 & 10,79 & 0,48 & 0,77 & 1,58 & 0,92 & 7,96 \\
\hline M2 & 88,85 & 11,15 & 0,39 & 0,74 & 1,53 & 0,87 & 8,50 \\
\hline M3 & 88,81 & 11,19 & 0,50 & 0,70 & 1,55 & 0,82 & 8,45 \\
\hline M4 & 88,88 & 11,12 & 0,53 & 0,75 & 1,53 & 0,89 & 8,31 \\
\hline Media & 88,94 & 11,06 & 0,47 & 0,74 & 1,55 & 0,87 & 8,30 \\
\hline $\begin{array}{l}\text { Desviación } \\
\text { Estándar }\end{array}$ & 0,19 & 0,19 & 0,06 & 0,03 & 0,03 & 0,04 & 0,24 \\
\hline
\end{tabular}

\subsection{Ensayos de actividad antimicrobiana}

Del ADV en las concentraciones del extracto crudo, se obtuvo para el factor tipo de bacterias una ligera tendencia $(P=0.09)$ de una diferencia entre los promedios de medición de los halos de inhibición debida al tipo de microorganismo analizado. Para el factor concentraciones del extracto etanólico crudo, se encontraron diferencias altamente significativas entre concentraciones $(P<0,001)$. Finalmente, no se encontraron evidencias de una interacción entre los dos factores $(P=0,11)$.

La prueba Tukey HSD para los promedios de las concentraciones del extracto etanólico crudo y su efecto en el halo de inhibición, (Tabla 5) perimitió identificar 3 grupos homogéneos. En el primer grupo se ubicaron el blanco y las dos concentraciones de extracto más bajas $\mathrm{C} 1$ y C2, en el segundo grupo la concentración C3 y en el último, la concentración $\mathrm{C} 4$, que fue la que produjo la máxima inhibición en el crecimiento de los microorganismos analizados.

Tabla 5. Comparación de promedios entre diámetro de inhibición microbiana y rangos Tukey correspondiente a las concentraciones probadas

\begin{tabular}{|l|l|l|l|l|}
\hline $\begin{array}{l}\text { Concentración de } \\
\text { extracto }\end{array}$ & Casos & Media LS & Sigma LS & $\begin{array}{l}\text { Grupos } \\
\text { Homogéneos }\end{array}$ \\
\hline BLANCO & 6 & 6,00 & 0,210819 & C \\
\hline C1 & 6 & 6,00 & 0,210819 & c \\
\hline C2 & 6 & 6,83 & 0,210819 & C \\
\hline C3 & 6 & 8,16 & 0,210819 & b \\
\hline C4 & 6 & 16,1667 & 0,210819 & a \\
\hline
\end{tabular}

En forma similar, se observó una diferencia altamente significativa $(P<0,001)$ entre los promedios de las mediciones de los halos de inhibición debida a las fracciones del extracto (C4), sin embargo, no se observaron diferencias entre los tipos de microorganismos sometidos al ensayo $(P=0,42)$, ni se constató una interacción entre los dos factores $(P=0,09)$. Los resultados obtenidos de la prueba Tukey HSD (Tabla 6), mostraron tres grupos homogéneos de promedios. Las fracciones $A, D$ y $E$ se ubicaron en el primer grupo, las fracciones $D, E$ y $C$ en el segundo y las fracciones $C$ y $D$ en el tercer grupo, en el mismo que se verificó una mayor inhibición del crecimiento de las bacterias estudiadas. 
Tabla 6. Pruebas de Múltiple Rangos para Diámetro de inhibición por Fracciones

\begin{tabular}{|l|l|l|l|l|}
\hline Fracciones & Casos & Media $\boldsymbol{L S}$ & Sigma $\boldsymbol{L S}$ & Grupos Homogéneos \\
\hline FA & 6 & 6,0 & 0,182574 & $\mathrm{a}$ \\
\hline FD & 6 & 6,16667 & 0,182574 & $\mathrm{ab}$ \\
\hline FE & 6 & 6,16667 & 0,182574 & $\mathrm{ab}$ \\
\hline FC & 6 & 6,83333 & 0,182574 & $\mathrm{bc}$ \\
\hline FB & 6 & 7,5 & 0,182574 & $\mathrm{c}$ \\
\hline
\end{tabular}

\subsection{Tamizaje fitoquímico}

En las cuatro fracciones logradas mediante el método de extracción sucesiva se llevaron a cabo las pruebas cualitativas de identificación de grupos fitoquímicos. La Tabla 7 recoge los resultados positivos obtenidos. En la fracción conseguida con éter de petróleo (FEP) se identificó la presencia de compuestos del tipo aceites/grasas y esteroles, así como la ausencia de alcaloides y lactonas. En la fracción clorofórmica (FCF), al igual que en la fracción etérea, se identificaron compuestos grasos y esteroles pero en una cantidad menor, mientras que los taninos se encontraron ausentes. Se identificó la presencia de esteroles y la ausencia de flavonoides y taninos en la fracción alcanzada usando acetato de etilo como solvente de extracción. En la fracción acuosa no se identificaron flavonoides, ni alcaloides, sin embargo, se reconoció la presencia de taninos y saponinas.

Tabla 7. Resultados obtenidos del tamizaje fitoquímico de las fracciones obtenidas por el método de maceración sucesiva

\begin{tabular}{|c|c|c|c|}
\hline $\begin{array}{l}\text { Solvente de } \\
\text { extracción }\end{array}$ & Ensayo de & Resultado & $\begin{array}{l}\text { Grupos fitoquímicos } \\
\text { detectados }\end{array}$ \\
\hline \multirow{2}{*}{$\begin{array}{l}\text { Éter de petróleo } \\
\text { (FEP) }\end{array}$} & Libermand-Burchard & +++ & Triterpenos y esteroides \\
\hline & Sudan & +++ & Aceites y grasas \\
\hline \multirow{2}{*}{$\begin{array}{l}\text { Cloroformo } \\
\text { (FCF) }\end{array}$} & Libermand-Burchard & ++ & Triterpenos y esteroides \\
\hline & Sudan & ++ & Aceites y grasas \\
\hline $\begin{array}{l}\text { Acetato de etilo } \\
\text { (FAE) }\end{array}$ & Libermand-Burchard & + & Triterpenos y esteroides \\
\hline \multirow[t]{2}{*}{$\begin{array}{l}\text { Agua } \\
\text { (FAC) }\end{array}$} & Cloruro férrico & ++ & $\begin{array}{l}\text { Taninos (hidrolizables y no } \\
\text { hidrolizables) }\end{array}$ \\
\hline & Espuma & + & Saponinas \\
\hline
\end{tabular}

De manera similar se ejecutaron pruebas cualitativas para la identificación de grupos fitoquímicos en las fracciones obtenidas a partir del extracto por maceración etanólica y los resultados positivos se resumen en la Tabla 8 . Las pruebas realizadas sobre la fracción $A$ indicaron la ausencia de alcaloides, mientras que los resultados obtenidos de la fracción $B$ confirmaron la presencia de esteroles y triterpenos. En la fracción $\mathrm{C}$ se identificaron varios grupos fitoquímicos: flavonoides, saponinas y taninos no hidrolizables y condensados, sin embargo, en la fracción $D$, que fué analizada por las mismas pruebas cualitativas, no se identificó ninguna familia de estos compuestos. Las pruebas de antocianos y antraquinonas dieron resultados negativos en las fracciones $C$ y D. Se descartó la presencia de glicósidos 
cardiotónicos y compuestos con agrupamiento lactónico como las cumarinas en la fracción E.

Tabla 8. Resultados obtenidos del tamizaje fitoquímico de las fracciones logradas por el método de extracción etanólica

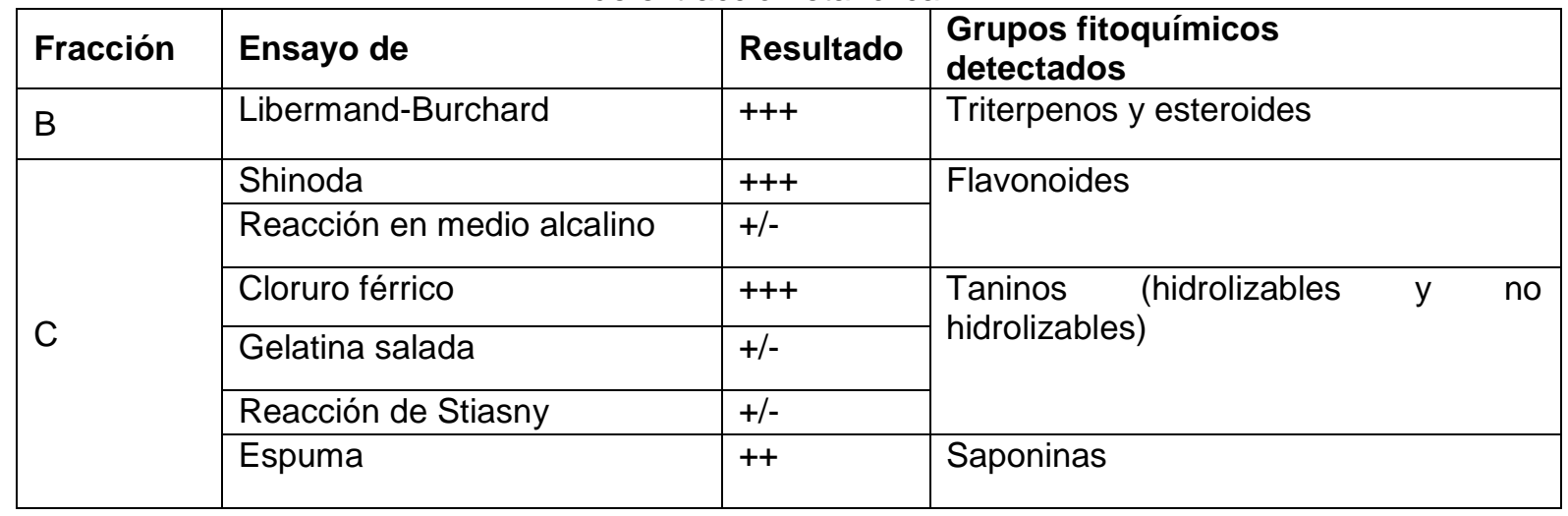

Al comparar los resultados de las pruebas fitoquímicas realizadas en los dos grupos de fracciones, alcanzadas por diferentes métodos de extracción, se evidenció el reconocimiento de grupos de compuestos fitoquímicos similares. Adicionalmente, se llevaron a cabo análisis por la técnica de cromatográfia en capa fina y sus resultados concuerdan con los correspondientes a las pruebas screening para la identificación de las familias de compuestos fitoquímicos. En las fracciones $\mathrm{B}$ y $\mathrm{C}$ se reconoció la presencia de esteroles y flavonoides respectivamente. Al revelar las placas obtenidas para esteroles y flavonoides se observaron 4 manchas en cada una de ellas. Para la identificación de flavonoides también fueron visualizadas las placas en UV y fluorescencia en donde se consideraron los colores generados, adicionalmente se calcularon los factores de retención o $\mathrm{R}_{\mathrm{f}}$ y los resultados se exponen en la Tabla 9.

Tabla 9. Rf obtenidos de la cromatografía de capa fina de las fracciones del extracto por maceración etanólica

\begin{tabular}{|c|c|c|c|c|}
\hline Fracción & $\begin{array}{l}\text { Grupo fitoquímico } \\
\text { identificado }\end{array}$ & $R_{f}$ & Color en UV & $\begin{array}{l}\text { Color } \\
\text { fluorescencia }\end{array}$ \\
\hline \multirow{4}{*}{ B } & \multirow{4}{*}{ Esteroles } & 0,24 & - & - \\
\hline & & 0,33 & - & - \\
\hline & & 0,40 & - & - \\
\hline & & 0,47 & - & - \\
\hline \multirow{4}{*}{ C } & \multirow{4}{*}{ Flavonoides } & 0,21 & Azul & $\mathrm{Si}$ \\
\hline & & 0,31 & Azul & $\mathrm{Si}$ \\
\hline & & 0,57 & Amarillo & No \\
\hline & & 0,90 & Amarillo & $\mathrm{Si}$ \\
\hline
\end{tabular}

Hasta nuestro mejor conocimiento en Ecuador no existe registro de otras investigaciones realizadas sobre la composición bromatológica de la cáscara de banano Musa paradisiaca producida en el país, razón por la cual los resultados obtenidos aportan a datos nacionales. Adicionalmente, el conocimiento del contenido general de los diferentes nutrientes presentes en la cáscara constituye la base para el planteamiento de posibles aplicaciones que con futuras investigaciones permitirá finalmente otorgarle usos 
innovadores a este subproducto. Los grupos de compuestos fitoquímicos identificados en los extractos se caracterizan por sus propiedades bioactivas y su potencial utilidad en la industria, no obstante los resultados obtenidos difieren de los generados en otras investigaciones. Niamah (2014) identificó, en el extracto metanólico crudo logrado por maceración, la presencia de compuestos fenólicos, flavonoides, saponinas, glicósidos y la ausencia de taninos. Mordi et al (2016) obtuvieron un extracto metanólico a través del método Soxhlet en el cual identificaron terpenos, taninos, esteroles y compuestos fenólicos en trazas, reconociendo además la ausencia de flavonoides. Ahmed (2015) identificó la presencia de saponinas, carotenoides, compuestos fenólicos, taninos y ausencia de alcaloides en el extracto etanólico crudo. Los diferentes métodos de preparación de muestra, extracción y los solventes usados son los posibles responsables de la discrepancia en los resultados, así como las variaciones en los metabolitos que generan las plantas dependiendo de las condiciones de producción (suelo, riego, clima, plagas, agroquímicos, entre otros).

Varias investigaciones con respecto a la actividad antimicrobiana de la cáscara de banano han sido realizadas en todo el mundo, no obstante, existe una notable diferencia entre los datos generados en esta investigación y los existentes. Chinnappan, et al (2013), concluyó que la cáscara de banano posee actividad antimicrobiana significantiva sobre Aeromona hydrophyla, Staphylococcus aureus y Pseudomona citrii, pero actividad nula frente a enterobacterias como Escherichia coli, Shigela sp., Klebsiella pneumoniae y Salmonella thyphi y thypinurium. Niamah (2014), evidenció una elevada actividad antimicrobiana sobre Staphylococcus aureus, Lactobacillus casei, Bacillus sp., y una actividad menor sobre Escherichia coli y Pseudomona aeruginosa. Ahmed (2015), reportó una elevada actividad sobre Staphylococcus aureus, $P$. aeruginosa así como en los hongos Aspergillus niger, Aspergillus flavus, Penicillium digitatum y Fusarium oxysporum; mientras que la actividad antimicrobiana sobre Escherichia coli fue menor. Mordi et al (2016), identificó una elevada actividad antimicrobiana sobre Escherichia coli, Staphylococcus aureus, Streptococcus spp., Klebsiella spp., y Pseudomona spp. Es importante recalcar que, pese a las investigaciones mencionadas, las cuales se realizaron en banano maduro de la misma especie, la fisiología de las plantas durante su desarrollo se ve afectada directamente por factores como el tipo de suelo, clima, cantidad de lluvias, época del año en la cual se produce, etc. Por lo tanto, existirán diferencias en la composición de los compuestos fitoquímicos presentes lo cual se traduce en variaciones en sus propiedades bioactivas, lo cual explicaría la discrepancia de los datos de actividad antimicrobiana. (Pavarini , D., Pavarini, S., Niehues, M., \& Lopes, N., 2012).

La existencia de actividad antimicrobiana y la presencia de grupos fitoquímicos específicos en el extracto de la cáscara de banano Musa paradisiaca, sustentan y justifican una posible utilización en la industria como producto biológico bactericida y es una alternativa sostenible, ecológica e innovadora, que orientándola adecuadamente permitiría inclusive enfrentar de alguna forma el cada vez más preocupante problema de resistencia a los antimicrobianos. Por lo tanto, investigaciones específicas podrían ser realizadas en este campo utilizando subproductos de banano producido en Ecuador.

\section{Conclusiones y recomendaciones}

La composición proximal de la cascara de banano de Ecuador indica que el $11 \%$ de su contenido corresponde a componentes con potenciales aplicaciones nutricionales ya que consisten en proteínas, compuestos inorgánicos (macro y micronutrientes) y carbohidratos, con bajo contenido de grasa. Asímismo, por los distintos grupos fitoquímicos encontrados como flavonoides, taninos, aceites y grasas, seguramente varias aplicaciones como antioxidante, bactericida, nutricionales y funcionales, podrían tomarse en consideración. Lo anterior contribuiría además a disminuir el tratamiento de una cantidad 
muy alta de subproductos agrícolas no solo en el país ya que en el mundo se consumen en el orden de millones de toneladas de banano por año.

Los extractos de cáscara de banano por maceración etanólica generan un efecto inhibitorio en el halo de crecimiento de las bacterias Staphylococcus aureus y Escherichia coli, y es dependiente de la concentración del extracto, lo cual indica que se debe al efecto de los componentes presentes en el extracto. Adicionalmente, se determinó que este efecto no difiere estadísticamente entre las dos bacterias utilizadas en el ensayo. Los ensayos de screening fitoquímico realizados en los extractos fraccionados permitieron determinar que las familias de compuestos fitoquímicos responsables de la actividad antimicrobiana de las cáscaras de banano corresponden a esteroles, triterpenos, flavonoides, taninos no hidrolizables y condensados, saponinas y compuestos fenólicos principalmente.

Finalmente, este tipo de estudios deben extenderse a otros subproductos de banano y otros productos ya que definitivamente podrían aportar al desarrollo sostenible de la humanidad, es decir, aportan a componentes sociales, económicos y ambientales lo que es clave en la economía circular que deberá implementarse o desarrollarse como principio productivo de los países.

\section{Bibliografía}

Ahmed, N. (2015). "Antioxidant, Antitumor, Antimicrobial Studies and Quantitative Phytoquemical Estimation of Ethanolic Extracts of Selected Fruit Peels". International Journal of Current Microbiology and Applied Sciences, 4 (5), 298-309.

A.O.A.C. Association of Analytical Chemist. (2000). "Oficial Methods of Analysis". Inc. Washington, D.C. E.U.A.

Chinnappan, S. et al. (2013). "Evaluation of microbial potential of different colored banana peels". International Journal of Preclinical \& Pharmaceutical Research. 4(2), 62-64.

Clinical and Laboratory Standards Institute. (2012, 01). MIC testing Volume 32. Number 2. Recuperado de http://antimicrobianos.com.ar/ATB/wp-content/uploads/2012/11/04DETERMINACION-DE-LA-SENSIBILIDAD-METODO-DE-DILUCION-2012.pdf (accedido el 07/02/2018).

Guil-Guerrero, J. et al. (2016)a. "Antimicrobial activity of plant-food by-products: A review focusing on the tropics". Livestock Science, 189, 32-39.

Guil-Guerrero, J. et al. (2016)b. "Plant Foods By-Products as Sources of Health-Promoting Agents". Agronomy Journal, 108, 1-16.

Guil-Guerrero, J. et al. (2016)c. "Plant-food by-products to improve farm-animal health". Animal Feed Science and Technology, 1-15.

MAGAP. (2014). Boletin Situacional Banano. Recuperado de http://sinagap.agricultura.gob.ec/phocadownloadpap/cultivo/2014/aboletinsituacional-banano-2014-actualizado.pdf (accedido el 07/02/2018)

Matos, F. (2009). Introdução à Fitoquímica Experimental (3 ed.). Fortaleza_Brasil. Edicóes UFC.

Mordi, R. et al. (2016). "Identification by GC-MS of the Components of oils of Banana Peels Extract, Phytochemical an Antimicrobial Analyses". Research Journal of Phytochemistry, 10, 39-44.

Niamah, A. (2014). "Determination, identification of bioactive compounds extracts from yellow banana peels and used in vitro as antimicrobial". International Journal of Phytomedicine, 6, 625-632.

Pavarini , D., Pavarini, S., Niehues, M., \& Lopes, N. (2012). "Exogenous influences on plant secondary metabolite levels". Animal Feed Science and Technology, 176 (1-4) pp: 516.

PROECUADOR. (2016). Sector Analysis Banano 2016. Recuperado de http://www.proecuador.gob.ec/pubs/banano-sector-analysis/ (accedido el 07/02/2018) 